March 31, 2005

Style: Applied Ergonomics

\title{
VASCULAR AND NERVE DAMAGE IN WORKERS EXPOSED TO VIBRATING TOOLS. THE IMPORTANCE OF OBJECTIVE MEASUREMENTS OF EXPOSURE TIME.
}

Lars Gerhardsson $^{1,2}$, Istvan Balogh ${ }^{2}$, Per-Arne Hambert ${ }^{3}$, Ulf Hjortsberg ${ }^{2}$, Jan-Erik Karlsson $^{2}$

1. Department of Occupational and Environmental Medicine, Sahlgrenska University Hospital, St Sigfridsgatan 85, SE-412 66 Göteborg, Sweden.

2. Department of Occupational and Environmental Medicine, University Hospital, SE-221 85 Lund, Sweden.

3. Skånehälsan AB, Linnégatan 34, SE-216 14 Malmö, Sweden.

Address for correspondence:

Lars Gerhardsson, Department of Occupational and Environmental Medicine, Sahlgrenska University Hospital, St Sigfridsgatan 85, SE-412 66 Göteborg, Sweden. FAX: +46-31-40 97 28. E-mail: lars.gerhardsson@ymk.gu.se 


\begin{abstract}
The aim of the present study was to compare the development of vibration white fingers (VWF) in workers in relation to different ways of exposure estimation, and their relationship to the standard ISO 5349, annex A. Nineteen vibration exposed (grinding machines) male workers completed a questionnaire followed by a structured interview including questions regarding their estimated hand-held vibration exposure. Neurophysiological tests such as fractionated nerve conduction velocity in hands and arms, vibrotactile perception thresholds and temperature thresholds were determined.
\end{abstract}

The subjective estimation of the mean daily exposure-time to vibrating tools was 192 minutes (range 18-480 minutes) among the workers. The estimated mean exposure time calculated from the consumption of grinding wheels was 42 minutes (range 1860 minutes), approximately a four-fold overestimation (Wilcoxon's signed ranks test, $\mathrm{p}<0.001)$. Thus, objective measurements of the exposure time, related to the standard ISO 5349, which in this case were based on the consumption of grinding wheels, will in most cases give a better basis for adequate risk assessment than self-exposure assessment.

Key words: Vibrating tools, vascular and neurological effects, dose estimation 


\section{INTRODUCTION}

The use of hand-held vibrating tools is common in many different professions and the tools vary in size, weight, acceleration amplitude and frequency. Exposure to vibrating tools may cause a variety of symptoms depicted as the hand-arm vibration syndrome (HAVS; Gemne 1997, Bovenzi 1998). The symptoms may be of vascular, neural, and muscular origin and may appear as digital vasospasm (vibration white fingers; VWF; Bovenzi et al 1995), sensorineural disturbances, and/or as muscular weakness and fatigue (Pyykkö 1986, Gemne 1997). The interindividual susceptibility, however, varies considerably and the dose-response relationships are not fully clarified.

A number of epidemiological studies performed in the 1960s and early 1970s reported a high prevalence (40\%-90\%) of VWF in forestry workers using chain saws with high frequency weighted acceleration in the order of $10-25 \mathrm{~m} \cdot \mathrm{s}^{-2}$ (rms-value; Bovenzi et al 1995). Later studies during the 1980s and 1990s showed a gradual decrease of the incidence and prevalence of VWF due to the enforcement of antivibrating (AV) chain saws and administrative measures undertaken to reduce the length and total duration of the vibration exposure. The same pattern is observed in several other occupations. Brammer (1982) calculated the relationship and latency time between the development of the VWF-syndrome and the vibration dose in studies of forestry workers, miners, grinders and rock drillers. In a recent study of forestry workers using chain saws (Bovenzi et al 1995), the overall prevalence of VWF was 23\%, 13\% in workers using only AV chain saws and $52 \%$ in workers using both non-AV and AV chain saws. Thus, the impact from AV preventive measures can be considerable. The expected prevalence of VWF increased almost linearly to either the eight-hour energy 
equivalent frequency weighted acceleration (A (8)) or the number of working years. The risk of VWF, however, was found to be lower than the one predicted by the international standard ISO 5349, and the authors thus, suggested revision of the standard.

Risk assessment of VWF is complicated due to the large number of factors that are involved in the development of the disease. Both overestimation and underestimation of the exposure duration may take place (Bovenzi 1998). Other variables of importance for the exposure dose include frequency weighting, frequency range, vibration magnitude and direction, and the use of AV tools or AV gloves (Griffin 1998). Also force and contact area, posture, body and hand temperature and genetic factors (subject variability) must be considered (Griffin 1997).

The aim of the present study was to compare dose-response calculations regarding the development of VWF based on different ways of exposure estimation, and their relationship to the standard ISO 5349, annex A. 


\section{METHODS}

The study comprised 19 male workers with more than three years of exposure to hand-held vibrating tools, mainly grinding machines. They had been working in five machine shops in the southern part of Sweden producing a variety of objects from steel doors to containers.

\section{Neurophysiological measurements}

\section{Tactilometry}

Measurement of the vibrotactile thresholds was done by delivering sinusoidal vibrations to the pulp of digits II and V, bilaterally, and registering the test subject's response (Lundström et al 1992; Strömberg et al 1998). The equipment used consisted basically of a modified audiometer of von Békésy-type. Vibrations at seven frequencies $(8-500 \mathrm{~Hz})$ were automatically delivered in an ascending order and transmitted to the finger pulp by a probe perpendicular to it. The probe was brought into light contact with the finger through a small hole in a table upon which the hand rested. The diameter of the probe was $2.5 \mathrm{~mm}$.

During testing, the subject was seated comfortably with his arm resting on a cushioned support. The amplitudes of the vibrations were modified using a hand-held switch. Pressing the button caused a gradual decrease of the amplitude of the stimulus whereas releasing the button caused an increase. The rate of amplitude-change was about $3 \mathrm{~dB} / \mathrm{s}$. This way a threshold at each frequency was obtained. It was defined as the average mid point between the registered upper and lower limens, expressed in decibels relative to $10^{-6} \mathrm{~m} / \mathrm{s}^{2} \mathrm{rms}$. The tactilogram was plotted on paper showing the 
frequencies on the $\mathrm{x}$-axis and, on an inverted scale, the vibration perception thresholds on the y-axis. By connecting a computer, the result for each subject could be compared with an age-corrected reference zone.

\section{Motor recordings}

The motor conduction velocities of the ulnar and median nerves were measured from the elbow to wrist by conventional techniques (Rosén, 1993; Rosén et al., 1993). The distal motor latencies for the ulnar and median nerves were measured by stimulation of the respective nerves with the cathode placed $20 \mathrm{~mm}$ proximal to the wrist crease of the respective nerve with the anode positioned $20 \mathrm{~mm}$ proximal to that. In the thenar muscles, the compound muscle action potential was recorded at maximal stimulation strength.

\section{Orthodromic sensory recordings}

Orthodromic sensory neurography was performed with surface electrodes measuring the sensory conduction velocities and the sensory nerve response amplitudes. The thumb and the long finger were stimulated with ring electrodes. Recordings were taken $20 \mathrm{~mm}$ proximal to the wrist crease. The reference electrode was placed a further $20 \mathrm{~mm}$ proximally. The latency was measured at the initiation of the negative nerve action potential. The nerve response amplitude was measured from the same point to the peak of the following negative potential (Rosén, 1993, Rosén et al., 1993). 


\section{Antidromic sensory recordings}

The fractionated conduction velocities of the median nerve across the carpal tunnel and from the palm to the third digit were measured by stimulating the nerve $20 \mathrm{~mm}$ proximal to the wrist crease and recording the nerve response from two sites, one in the palm with surface electrodes and one on the third digit with ring electrodes. The nerve was stimulated at the elbow, at the wrist, and in the palm with an inter-electrode distance of $20 \mathrm{~mm}$. The amplitude of the antidromic sensory nerve response recorded from the third digit was also measured. Further details of the methods have been given elsewhere (Rosén, 1993; Rosén et al 1993).

\section{Vibrometry}

Vibration thresholds were measured by the method described by Goldberg and Lindblom (1979; Vibrameter, Somedic, stimulation frequency - $100 \mathrm{~Hz}$ ) for the flexor surface of the distal phalanx of each finger in both hands with the finger resting on a pad filled with rice. The values given are means of the thresholds at increasing and decreasing amplitudes on several trials (Rosén, 1993).

\section{Temperature thresholds}

The temperature thresholds for cold and warmth were examined using a Somedic, Thermotest ${ }^{\circledR}$ equipment. Starting at $30{ }^{\circ} \mathrm{C}$, the index finger and little fingers of both hands were tested by repeatedly applying linear increases or decreases in temperature. The threshold was defined as the mean difference in temperature between the starting level and the one at which the patient perceived a change (Rosén, 1993; Strömberg et al, 1999). 


\section{Exposure assessment}

All workers passed a physical examination followed by a structured interview, which was based on a questionnaire with a number of questions regarding exposure, subjective symptoms and background factors. The type and number of tools, daily exposure time for each tool, number of working days per week and per year, as well as the number of working years were used to calculate the vibration exposure for each worker. The time of exposure to vibrating tools, expressed in minutes per day (individual vibration dose), was calculated in two ways: 1) from the subjective estimation by the worker based on information from the questionnaire and from the structured interview, and 2) from calculations based on the registered grinding wheel consumption at the companies, on a yearly basis. Routinely, each grinding operation by the worker was registered by a time clock. Thus, the mean lifetime of the grinding wheels purchased by the company could be calculated.

The vibration level was measured according to ISO 5349 during work by a small accelerometer (Brüel \& Kjær 4374), charge amplifier (B \& K 2626) and a signal analyser (B \& K 2033).

\section{STATISTICS}

The different exposure measures and neurophysiological variables did not follow a normal distribution. Thus, nonparametric statistical methods were applied (e.g. Wilcoxon's signed ranks test, Spearman's correlation coefficients - rho). Statistical significance was considered to be reached when $\mathrm{p}<0.05$. Linear regression analysis was applied to evaluate the relationship between neurophysiological variables on the one hand and age and different exposure measures, on the other. Model fits were 
checked by means of residual analysis (Altman 1991). All analyses were performed with the Statistical Package for the Social Sciences (SPSS, version 10.0).

\section{RESULTS}

The 19 platers/grinders had a mean-age of 43 years (range 29-60 years) and a median exposure-time of 20 years (range 3-47 years). Thirteen of the workers showed subjective symptoms of neuropathy and five of them also showed signs and symptoms of VWF. Of the remaining six workers, two had developed vibration-induced white fingers without concurrent symptoms and signs of distal neuropathy, and four were healthy with no clinical symptoms.

The subjective estimation by the workers of the daily mean exposure-time to vibrating tools was 192 minutes (range 18-480 minutes), while the estimated mean exposuretime calculated from the consumption of grinding wheels was 42 minutes (range 1860 minutes; Wilcoxon's rank signed test, $\mathrm{p}<0.001)$. The measured frequencyweighted acceleration levels from the 10-12 tools that were used by the workers varied between 121 and $145 \mathrm{~dB}$ re $1 * 10^{-6} \mathrm{~m} / \mathrm{s}^{2}$ (corresponding to $1-17 \mathrm{~m} / \mathrm{s}^{2}$ ). The measurements showed variations up to $10 \mathrm{~dB}$ for the frequency-weighted acceleration level during work with grinding wheels.

Based on the calculated group mean exposure time about $25 \%$ of the exposed workers would develop signs of VWF after 10 years of exposure according to ISO 5349.

(Figure 1). This estimate is rather close to the prevalence of VWF detected in the group, $7 / 19$ (37\%). These figures can be compared with the self-assessed group mean 
exposure time where $65 \%$ would develop VWF, which is a clear overestimation of the risk.

The correlation matrix shows good agreement $\left(\mathrm{r}_{\mathrm{s}}=0.73 ; \mathrm{p}=0.002\right)$ between the objective estimation of the vibration dose and the total number of working years during the latest employment (Table 1). The agreement was also fairly good between the subjective and objective estimation of the vibration dose during the latest employment $\left(\mathrm{r}_{\mathrm{s}}=0.56 ; \mathrm{p}=0.03\right)$. As expected the correlation between the subjective estimation of the lifetime exposure dose and the total number of working years with vibrating tools was somewhat lower $\left(\mathrm{r}_{\mathrm{s}}=0.49, \mathrm{p}=0.045\right)$.

The perception thresholds for vibration exposure showed a positive relationship with age and the total number of working years with vibrating tools. Contrary, a negative relationship was observed between nerve conduction velocities in motor and sensory nerves in the arms on the one hand, and age at the time of the study or total number of working years with vibrating tools on the other, e.g. for the orthodromic sensory recording of dig III of the right hand $\left(r_{s}=-0.62, p=0.008\right.$ and $r_{s}=-0.63, p=0.007$, respectively). The following regression equation was obtained:

Orthodromic sensory recording in dig III, right hand $=56-0.27 \times$ total number of working years with vibrating tools $\left(\mathrm{r}_{\mathrm{s}}=0.50 ; \mathrm{p}=0.039\right)$. In a multivariate regression model, however, age at the time of the study but not total number of working years with vibrating tools was included in the model: Orthodromic sensory recording in dig III, right hand $=73-0.47 \times$ age $\left(r_{s}=0.63 ; p=0.006\right)$. The temperature thresholds, however, were not significantly related to age or total number of working years. Thus, 
perception thresholds for vibration and nerve conduction velocities were the most sensitive outcome measures in this study.

\section{DISCUSSION}

The prevalence of VWF among healthy men is reported to be about 5\% (Gemne et al., 1987). For healthy women similar estimations would give significantly higher values, around 22\% (Olsen and Nielsen 1978).

Different ways of estimating the lifetime vibration dose have been used over the years. A commonly used summation index is lifetime vibration dose $=$ frequencyweighted acceleration measured on the vibrating tool $\mathrm{x}$ the estimated daily exposure in hours x number of working days per year x number of working years. A cumulative vibration exposure of $24000 \mathrm{mh} / \mathrm{s}^{2}$ corresponds according to ISO 5349 to a $10 \%$ prevalence of vascular disorders after 10 years exposure to a $4 \mathrm{~h}$-frequency weighted acceleration level $\left(\mathrm{a}_{\mathrm{h}, \mathrm{w}}\right)_{4 \mathrm{~h}}$ of $2.9 \mathrm{~m} / \mathrm{s}^{2}$.

The outcome of the risk assessment based on the ISO standard 5349, annex A, was dependent on the method of exposure estimation. The subjectively estimated time of exposure was about four times longer than the calculated time of exposure to the tools. As evident from figure 1 , the subjectively estimated vibration exposure gave a risk of VWF of about $65 \%$, according to the ISO standard 5349, annex A. On the other hand, the objectively estimated vibration exposure gave a risk of VWF of about $25 \%$, which is slightly lower as compared with the observed outcome in this study 
$(7 / 19=37 \%)$. Accordingly, objective measurements in most cases will give a better basis for adequate risk assessment than subjective estimations.

In some studies, however, the subjective rating of the vibration exposure time is rather close to the values obtained by objective measurements (Nilsson et al 1989). In their study the subjective rating of the time using grinders (74 min/day) and hammers (29 $\mathrm{min} /$ day) was rather close to the objective measurements giving 83 and 22 minutes, respectively.

The vibration exposure figures given by the worker can be validated by e.g. observing the worker and using a watch to measure the time when the workers is exposed to hand-arm vibration. An alternative is estimation based on rating of video-recorded work tasks and information from questionnaires or diaries.

The substantial difference regarding the subjective and objective estimations of the time of exposure to vibrating tools in this and some other studies are probably due to the large number of factors influencing the human response, e.g. frequency, intensity, duration and direction of the vibrations, grip force, working posture as well as the large biological variation among individuals (Gemne 1997). Findings in several epidemiologic studies have shown poor agreement between the risk of VWF observed in various occupational groups and that predicted by the ISO 5349 model. Both overestimations and underestimations of the occurrence of VWF have been reported. Overestimations are more common in studies of workers using tools with a predominantly low-frequency percussive action, e.g. road breakers, rock drills and stone hammers (Bovenzi 1998). In one experimental study, the frequency weighting 
given in ISO 5349 was found to overestimate the acute effects of vibration exposure on the digital circulation at frequencies about $16 \mathrm{~Hz}$ (Bovenzi et al 2000). Since the ISO frequency-weighting curve increases the importance of low-frequency vibration, it can be discussed whether or not the evaluation of such vibration exposure according to the ISO standard adequately reflects the risk for adverse vascular effects. On the other hand, other epidemiologic studies have found that the ISO weighting may underestimate the vascular effects of vibrating tools containing high frequency components. This could mean that high-frequency vibration could induce a digital vasospasm that is more powerful than what may be caused by low-frequency vibration (Bovenzi 1998). In a Swedish study of 10 dental hygienists, the use of an ultrasonic scaler was measured during three consecutive weeks using a timeregistration device ( $\AA$ kesson et al 20001). Every period of activation during a working day was cumulatively added. This objective measurement was compared with subjective estimations by use of a diary and interview methods. The measured total daily exposure time was shorter than expected, on average 12 minutes. A great variation regarding self-estimation of exposure time, however, was found both between and within the subjects. The self-assessed duration of exposure was overestimated, on average three times higher with a diary, and even more, eight times at the interviews. Hence, direct measurements are preferable for adequate risk assessment.

It must also be considered that current standards do not reflect the impact from vibration impulsiveness, the direction of vibration, area of contact, the intermittence of exposure (Gemne 1994), work methods, contact force, or posture (Griffin 1997). 
If using a four hour or eight hour energy equivalent exposure the vibration dose may come from one continuous exposure or from the same total duration produced by a number of shorter exposure periods with possibilities to rest between the exposures. It is highly probable that the risk of adverse effects from vibration exposure may differ between these exposure situations. In the Human Vibration Directive 2002/44/EC of the European Parliament and of the Council of June 2002 (EU 2002) new standards are enforced. The daily exposure action value standardized to an eight-hour reference period was set at $2.5 \mathrm{~m} / \mathrm{s}^{2}$. The corresponding daily exposure limit value standardized to an eight-hour reference period was set at $5 \mathrm{~m} / \mathrm{s}^{2}$. Moreover, the employer shall ensure that vibration exposed workers will receive appropriate information and training to prevent the development of VWFs. Safe working practices to minimise the exposure to mechanical vibration should be undertaken. Objective measurements of the vibration exposure and estimations of the vibration dose will facilitate risk assessment and increase the possibilities for preventive actions. Other factors of importance in this context are the risk of underestimating the effect due to diagnostic uncertainties, the biological variation and the healthy worker effect (Gemne 1997). Sensitive people developing early signs and symptoms of HAVS may leave the work, and the workers staying for many years may, thus, be a population of survivors.

The correlation matrix in table 1 shows the difficulties in obtaining a relevant dose estimate. The best correlations in this study were noted between the subjective and objective estimate of the vibration dose during the latest employment as well as during all years of work with vibrating tools (Table 1). Age was rather closely related to the total number of working years with vibrating tools, which together with the limited sample size complicates further comparisons, e.g. multivariate modelling. 
In accordance with a number of papers the vibrotactile thresholds obtained by tactilometry showed a positive correlation to the vibration exposure measures used in this study. The neurophysiologic measurements (motor recordings, orthodromic and antidromic sensory recordings) showed as expected a negative relationship to different exposure measures, e.g. age and total number of working years with vibrating tools. This pattern has been confirmed in a number of studies. The temperature thresholds, on the other hand, did not show a clear relationship to the different dose estimates.

In conclusion, precise dose estimations of the vibration exposure are difficult to obtain as many factors are involved in the vibration transmission from the tool to the hand-arm system. Self-reporting of the vibration exposure may be due to individual estimation difficulties but may also depend on the psychological disposition of the worker as regards the tendency to overestimate or underestimate such an exposure. In many cases, however, subjective estimation of the duration time will give a significant overestimation of the vibration dose as compared with objective measures, which must be considered when evaluating the risk for the development of VWF in exposed subjects. 


\section{REFERENCES}

Akesson, O., Balogh, I., Skerfving, S., 2001. Self-reported and measured time of vibration exposure at ultrasonic scaling in dental hygienists. Appl. Ergonomics 32, $47-51$.

Altman, D.G., 1991. Practical Statistics for Medical Research. Chapman \& Hall, London.

Bovenzi, M., Franzinelli, A., Mancini, R., Cannavá, M.G., Maiorano, M., Ceccarelli, F., 1995. Dose-response relation for vascular disorders induced by vibration in the fingers of forestry workers. Occup. Environ. Med. 52, 722-730.

Bovenzi, M., 1998. Exposure-response relationship in the hand-arm vibration syndrome: an overview of current epidemiology research. Int. Arch. Occup. Environ. Health 71, 509-519.

Bovenzi, M., Lindsell, C.J., Griffin, M.J., 2000. Acute vascular responses to the frequency of vibration transmitted to the hand. Occup. Environ. Med. 57, 422-430.

Brammer, A.J., 1982. Relations between vibration exposure and the development of the vibration syndrome: In: Brammer, A.J., Taylor W, eds. Vibration effects on the hand and arm in industry. New York: John Wiley, 283-290. 
EU, Directive 2002/44/EC of the European Parliament and of the Council of 25 June 2002 on the minimum health and safety requirements regarding the exposure of workers to the risks arising from physical agents (vibration) (sixteenth individual Directive within the meaning of Article 16(1) of Directive 89/391/EEC).

Gemne, G., Pykko, I., Taylor, W., Pelmear, P.L., 1987. The Stockholm Workshop scale for the classification of cold-induced Raynaud's phenomenon in the hand-arm vibration syndrome (revision of the Taylor-Pelmear scale). Scand. J. Work Environ. Health 13, 275-278.

Gemne, G., 1994. Where is the research frontier for hand-arm vibration? Scand. J. Work Environ. Health 20, 90-99.

Gemne, G., 1997. Diagnostics of hand-arm system disorders in workers who use vibrating tools. Occup. Environ. Med. 54, 90-95.

Goldberg, J.M., Lindblom, U., 1979. Standardised method of determining vibratory perception thresholds for diagnosis and screening in neurological investigation. J. Neurol. Neurosurg. Psychiatry 42, 793-803.

Griffin, M.J., 1997. Measurement, evaluation, and assessment of occupational exposures to hand-transmitted vibration. Occup. Environ. Med. 54, 73-89.

Griffin, M.J., 1998. Evaluation of the effectiveness of gloves in reducing the hazards of hand-transmitted vibration. Occup. Environ. Med. 55, 340-348. 
ISO 5349. Mechanical vibration - Guidelines for the measurement and the assessment of human exposure to hand-transmitted vibration. International Organization for Standardization, Geneva (1986).

Lundström, R., Strömberg, T., Lundborg, G., 1992. Vibrotactile perception threshold measurements for diagnosis of sensory neuropathy. Description of a reference population. Int. Arch. Occup. Envion. Health 64, 201-207.

Nilsson, T., Burström, L., Hagberg, M., 1989. Risk assessment of vibration exposure and white fingers among platers. Int. Arch. Occup. Environ. Health 61, 473-481.

Olsen, N., Nielsen, S.L., 1978. Prevalence of primary Raynaud phenomena in young females. Scand. J. Clin. Invest. 38, 761-764.

Pyykkö, I.. 1986. Clinical aspects of the hand-arm vibration syndrome. A review. Scand. J. Work Environ. Health 12, 439-447.

Rosén, I., 1993. Neurophysiological diagnosis of the carpal tunnel syndrome: evaluation of neurgraphic techniques. Scand. J. Plast. Reconstr. Hand Surg. 27, 95101.

Rosén, I., Strömberg, T., Lundborg, G., 1993. Neurophysiological investigtion of hands damaged by vibration: comparison with idiopathic carpal tunnel syndrome. Scand. J. Plast. Reconstr. Hand Surgery 27, 209-216. 
Stromberg, T., Dahlin, L.B., Lundborg, G., 1998. Vibrotactile sense in the hand-arm vibration syndrome. Scand. J. Work Environ. Health, 24, 495-502.

Stromberg, T., Dahlin, L.B., Rosén, I., Lundborg, G., 1999. Neurophysiological findings in vibration-exposed male workers. J. Hand Surg. 24, 203-209. 
Figure 1. Risk assessment for the 19 workers according to ISO 5349, Appendix A as individuals ( $($ ), as well as group means, based on self assessment ( $\square$ ) of the daily exposure time respectively calculated ( $\square$ ) time.

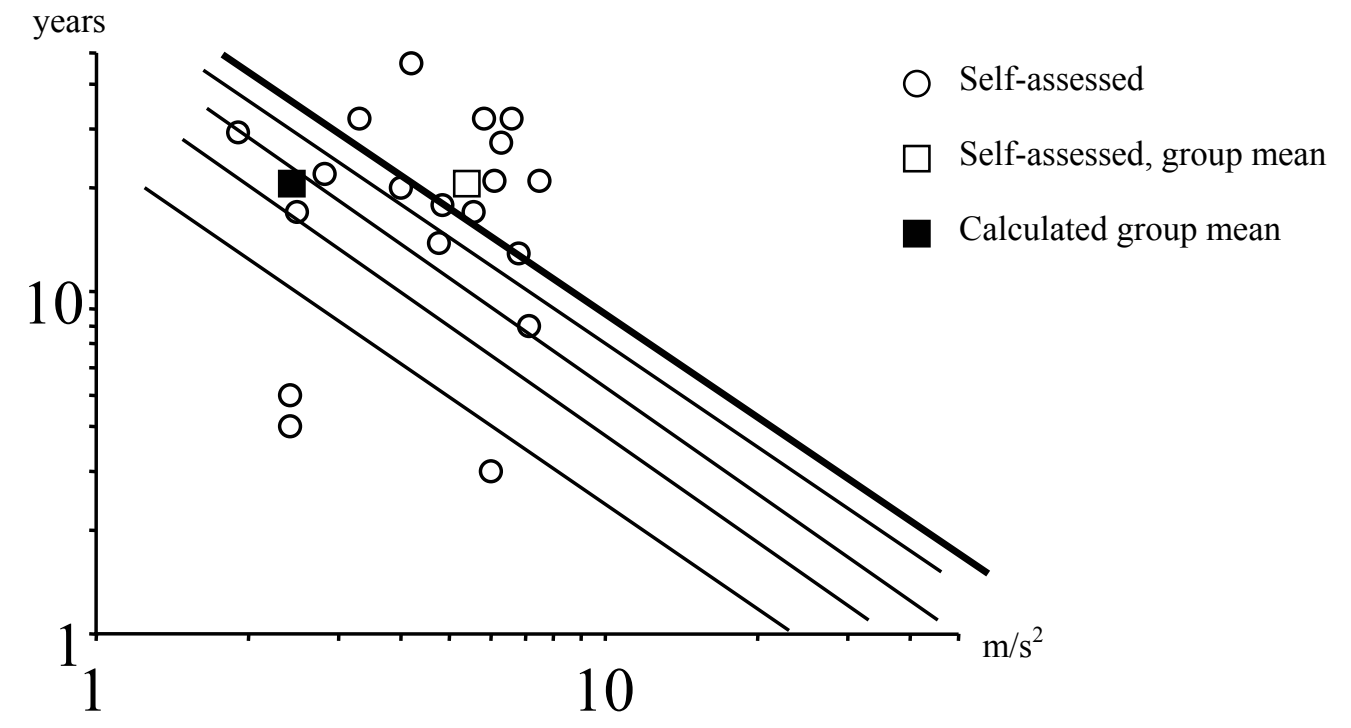


Table 1. Correlation matrix (Spearman's rho; p-values) between different vibration exposure dose estimates. Age $=$ age at the time of the study, TWY $=$ total number of working years with vibration tools, WYL = total number of working years with vibrating tools during the latest employment, $\mathrm{ODL}=$ objective estimate of vibration dose during the latest employment, $\mathrm{SDL}=$ subjective estimate of vibration dose during the latest employment, SDT = subjective estimate of the vibration dose during all years of work with vibrating tools.

\begin{tabular}{|c|c|c|c|c|c|}
\hline Age Age & $\begin{array}{l}\text { TWY } \\
0.57 \\
(0.17)\end{array}$ & $\begin{array}{l}\text { WYL } \\
\text { NS }\end{array}$ & $\begin{array}{l}\text { ODL } \\
\text { NS }\end{array}$ & $\begin{array}{l}\text { SDL } \\
\text { NS }\end{array}$ & $\begin{array}{l}\text { SDT } \\
\text { NS }\end{array}$ \\
\hline TWY & & $\begin{array}{l}0.47 \\
(0.059)\end{array}$ & $\begin{array}{l}0.59 \\
(0.019)\end{array}$ & NS & $\begin{array}{l}0.49 \\
(0.045)\end{array}$ \\
\hline WYL & & & $\begin{array}{l}0.73 \\
(0.002)\end{array}$ & $\begin{array}{l}0.59 \\
(0.013)\end{array}$ & NS \\
\hline ODL & & & & $\begin{array}{l}0.56 \\
(0.03)\end{array}$ & NS \\
\hline SDL & & & & & $\begin{array}{l}0.56 \\
(0.02)\end{array}$ \\
\hline
\end{tabular}

